\title{
Application of prodigiosin as a colorant for polyolefines
}

\author{
Irina Ryazantseva*, Irina Andreyeva \\ Kazan Institute of Biochemistry and Biophysics, Russian Academy of Sciences, Kazan, Russian Federation \\ Email:
}

Received 6 December 2013; revised 15 January 2014; accepted 23 January 2014

Copyright (C) 2014 Irina Ryazantseva, Irina Andreyeva. This is an open access article distributed under the Creative Commons Attribution License, which permits unrestricted use, distribution, and reproduction in any medium, provided the original work is properly cited. In accordance of the Creative Commons Attribution License all Copyrights (c) 2014 are reserved for SCIRP and the owner of the intellectual property Irina Ryazantseva, Irina Andreyeva. All Copyright (C 2014 are guarded by law and by SCIRP as a guardian.

\section{ABSTRACT}

Serratia marcescens strain 9986 is a producer of prodigiosin used as a dye of polyolefines (polyethylene, ultratene). The biosynthesis of pigment was closely connected with controlled growth parameters. A prodigiosin yield $0.2-0.4 \mathrm{mg}$ per 1 of culture medium in the batch culture under aerobic conditions was obtained. Prodigiosin was extracted from crude biomass treated by $0.1 \%$ of sodium dodecyl sulfate (SDS). This novel elaborated stage is necessary for thermostability a dye in polymer. The consumption of prodigiosin preparation is more economical in the technology of the coloration of polyolefines. The elaborated method has been manufactured for dyeing polyethylene by biological pigment-articles of the common use corresponding to the technological standard.

\section{KEYWORDS}

\section{Serratia marcescens; Pigment; Prodigiosin; Polyolefines; Dyeing}

\section{INTRODUCTION}

Biological pigments are of high commercial importance, for instance, a photosynthetic pigment phycocyanin being a natural blue colorant is utilized as a food dye [1], the others in pharmaceutics, cosmetic etc. In this view the interest to the pigments derived from natural source is growing as against the potential toxicity of some organic dyes and synthetic pigments.

The requirements for general organic pigments used for polymer coloration, namely, wide acceptable temperature range, fine dispersion in the carrying material, lightness stability, a good migratory stability, are challenging, and result in high cost of organic pigments. At the same time, the supply of the raw materials for the

${ }^{*}$ Corresponding author. synthetic pigments is limited by strict ecological and polymer coloration requirements. The microbial pigments being secondary metabolites are the diversified composition according to their structure and may be attributed to the ecologically safe compounds in the chem.ical industry.

The development of products based on new biological chromophores is a novel aspect in biotechnology. Serratia marcescens synthesizes the membrane linked red pigment prodigiosin-pyrryldipyrrylmethene linked to the membrane [2,3]. Prodigiosin is a well known pigment and numerous factors have been reported to affect its production in the culture [4-7]. In this search, the economically simple culture medium on the base of the efficient, environmentally safe components for prodigiosin synthesis was used. The necessary bulk of biomass as the initial raw material for pigment isolation has been provided.

The present study aims at revealing the effect of the raw material quality on yield of pigment in the batch culture of Serratia marcescens and elaborating the method of the extraction from biomass met requirements for coloration of polyolefines by pigment preparation prodigiosin.

\section{EXPERIMENTAL}

\subsection{Bacterial Strain and Culture Conditions}

The pigmented strain Serratia marcescens strain 9986, in this study was obtained from the Culture Collection of Kazan Federal University (Russia). The culture was maintained in the liquid medium [5] and also in broth containing meat peptone $\left(5 \mathrm{~g} \cdot \mathrm{l}^{-1}\right)$ and glycerol $\left(10 \mathrm{~g} \cdot \mathrm{l}^{-1}\right)$ [2] as a standard medium for cultivation. The strain was cultivated in flasks $250 \mathrm{ml}$ (total of $50 \mathrm{ml}$ ), pH 7. 2, at $28^{\circ} \mathrm{C}$, at $180 \mathrm{rpm}$ on a shaker (IS-971 R IEIO Tech., Korea) in the darkness. The culture was grown in flasks 2.0 l containing 1, 1 l growth medium at the same conditions of the incubation for accumulation of pigmented biomass 
under controlled factors of the fermentation. It was also grown in two variants on the medium with meat peptone $\left(5 \mathrm{~g} \cdot \mathrm{l}^{-1}\right)$ (Sigma) or with peptone enzymatic digest from soybean $\left(5 \mathrm{~g} \cdot \mathrm{l}^{-1}\right)$ (Fluka).

Cell growth was determined at $670 \mathrm{~nm}$ (OD) so that the optical density of growing culture and spectrum of prodigiosin $(535 \mathrm{~nm}$ ) have been divided.

The experiments were repeated three times and measurements were made for each time point of the incubation.

\subsection{Prodigiosin Essay}

To extract prodigiosin $1.0 \mathrm{ml}$ of cultural liquid from grown cells or from cell suspension to $9.0 \mathrm{ml}$ of acidified ethanol $(10 \mathrm{ml}$ of ethanol and $1 \mathrm{ml}$ of $1 \mathrm{~N} \mathrm{HCl})$ added. Time of extraction made 20-min, the cell debris was removed by centrifugation at $9200 \mathrm{~g}$, for $10 \mathrm{~min}, 5^{\circ} \mathrm{C}$. The prodigiosin concentration was measured spectrophotometrically at $535 \mathrm{~nm}$ in the growing culture and in the cellular suspension on the scanning spectrophotometer a Lambda-25 (Perkin Elmer, USA). Pigment concentration was calculated using extinction coefficient for prodigi$\operatorname{osin}\left(51.5 \times 10^{3} \mathrm{l} \cdot \mathrm{g} \cdot \mathrm{cm}\right)[4]$.

Definition the Size of the Pigment Protein Particles The size of the pigment protein particles was determined to the method of dynamic light scattering (DLS) [8].

\subsection{Treatment of Biomass for Prodigiosin Preparation}

The method of the extraction from biomass of pigment preparation prodigiosin was elaborated according to technology of dyeing polyolefines. The grown pigmented culture was subjected to centrifugation at $6000 \mathrm{~g}$, for 15 min, $5^{\circ} \mathrm{C}$. In the crude pigmented biomass the detergents sodium dodecylsulphate (SDS) (0.1 - $0.5 \mathrm{wt} \%)$ or nonionic Triton X-100 (10.0 mM) were introduced. The solubilizable cell suspension dissolved in $50 \mathrm{mM}$ phosphate buffer ( $\mathrm{pH}$ 7.0) was tested on the lightfastness of prodigiosin by exposing the pigment suspension under lighting the fluorescent lamp (Hitachi) at a flux of 45.0 $\mu \mathrm{M}$ photons $\mathrm{m}^{-2} \cdot \mathrm{s}^{-1}$ until $48 \mathrm{~h}$ (Table 1 ). In the elaborated method the treatment of the crude biomass by 0.1 wt\% SDS was undertaken. The solubilization of the pigmented biomass by SDS is a necessary stage for later use. Then an effective extraction of the pigment preparation from solubilizable biomass by polar organic solvent ethanol no less than 4 - 5 times was consisted Pigment alcohol solution was concentrated in the rotary vacuum evaporator under temperature $62.0^{\circ} \mathrm{C}-63.0^{\circ} \mathrm{C}$.

The production of the coloration polymeric compositions by pigment preparation prodogiosin was described $[9,10]$.
Table 1. Lightfastness of the pigment suspension treated by detergents (\%).

\begin{tabular}{cccc}
\hline \multirow{2}{*}{ Time (hour) } & \multicolumn{3}{c}{ Illumination $\left(45.0 \mu \mathrm{M} \mathrm{photon} \mathrm{m}^{-2} \cdot \mathrm{s}^{-1}\right)$} \\
\cline { 2 - 4 } & Suspension (control) & Triton X-100 & SDS \\
\hline 0 & 100 & 100 & 100 \\
24 & $38.0 \pm 1.8$ & $42.0 \pm 2.4$ & $81.0 \pm 2.9$ \\
48 & $25.0 \pm 2.2$ & $24.0 \pm 3.6$ & $74.0 \pm 2.7$ \\
\hline
\end{tabular}

\subsection{Dyeing of Polyolefines by the Prodigiosin Preparation}

The bright red prodigiosin colour of the concentrates and the masterbatches were achieved by the method of polymer dyeing in the Central Laboratiry of J-SCo "Kazanorgsyntese" [11]. In this study the polyethylene and the ultrathene in granules were applied for coloring elaboration. The manufacture of the polymer compositions was carried out on the press (Polymix 110 P, Schwabenthan, Germany) by introduction granular polymer. The process of rolling was at: the temperature $150^{\circ} \mathrm{C}-155^{\circ} \mathrm{C}$ on the front roller and $135^{\circ} \mathrm{C}-140^{\circ} \mathrm{C}$ on the back roller. The time of rolling process was $20-25 \mathrm{~min}$. The pigment suspension was introduced gradually up to rolled polymer sheet for the equilibrium coloration of the dyed-stuff. The manufactured polymer sheet served as a colored concentrate (the colour masterbatches additives). The press for compressing various thickness of dyed samples was used (Fantune, Holland). The cutting out was applied for the preparation of dyed samples in the process tests of their quality (CELST, Italy). Dyed form of molded plates-dimensions of $20.0 \times 20.0 \mathrm{~mm}$ and the thickness of $1.0 \pm 0.1 \mathrm{~mm}$ were also evaluated according to the technical standard.

The pigment preparation prodigiosin was used in the technology dyeing as a thick suspension-concentrate without spraying in the air.

\section{RESULTS AND DISCUSSION}

\subsection{Cell Growth and Prodigiosin Production Conditions}

In this elaboration the success of a biotechnological process for exploitation at industrial level of prodigiosin has been revealed. It was found the novelty of the realizable advantages associated with more economical consumption of prodigiosin preparation in the dyeing polyethylene concentrates, a happy choice the conditions for extraction pigment from biomass useful to the colorant technology, the brief time of fermentation etc.

The biosynthesis of prodigiosin by pigmented strain of Serratia marcescens under aerobic conditions in the batch culture is realized. The pigment production is 
highly variable among species Serratia and it depends on many factors such as the specific strain, the temperature, the incubation time, the illumination, the $\mathrm{pH}$ medium and others $[2,5,12]$. The illumination conditions (light/darkness) affected both the biosynthesis of prodigiosin and energetic metabolism of the pigmented strain ATCC 9986 Serratia marcescens were shown [8].

The phenomenon of prodigiosin production was discovered in the batch culture at temperature $28^{\circ} \mathrm{C}$. Moreover, the content of prodigiosin in the culture grown in darkness was higher than that grown in light. The pigment biosynthesis beginning from 18 - 20 hours of incubation of culture was revealed. A maximum of pigment synthesis in the culture was reached at the end of exponential growth phase and initial stationary phase within 50 - 54 hours of the incubation that corresponded to the stage of active cell growth (Figure 1). In this way the time of fermentation is mostly preferably for pigment isolation from fermented broth. However, the accumulation of prodigiosin in the culture growing in darkness was higher than that grown in the light, $42.0-60.0$ $\mu \mathrm{g} \cdot \mathrm{ml}^{-1}$ and 30.0 - $36.0 \mu \mathrm{g} \cdot \mathrm{ml}^{-1}$, respectively. Dark culture retained its bright red color to a dark cherry one up to 7 - 9 days and the pigmented cells had been already lysed.

Serratia marcescens, like other Enterobacteriaceae, grow well on ordinary media and other differential and selective media [13-15]. The regular liquid medium currently being used for prodigiosin biosynthesis is nutrient meat peptone-glycerol broth. It was used as a growth medium for Serratia marcescens strain 9986 where the glycerol was the carbon source and a peptone was as the nitrogen source. The cheap medium peptone digest from soybean as economically cheap source was used also in the nutrition medium. Figure 2 shows the culture growth

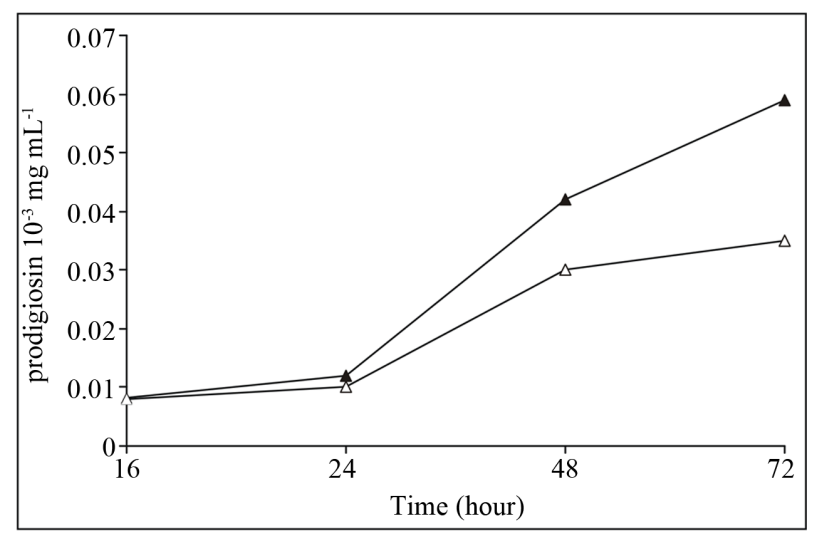

Figure 1. The biosynthesis of prodigiosin in the light $(O)$, in darkness $(\bullet)$ Serratia marcescens strain 9986 was incubated in broth containing meat peptone and glycerol. The pigment synthesis (E $535 \mathrm{~nm}$ ) in darkness was higher by comparison in the light $42.0-60.0 \mu \mathrm{g} \cdot \mathrm{ml}^{-1}$.

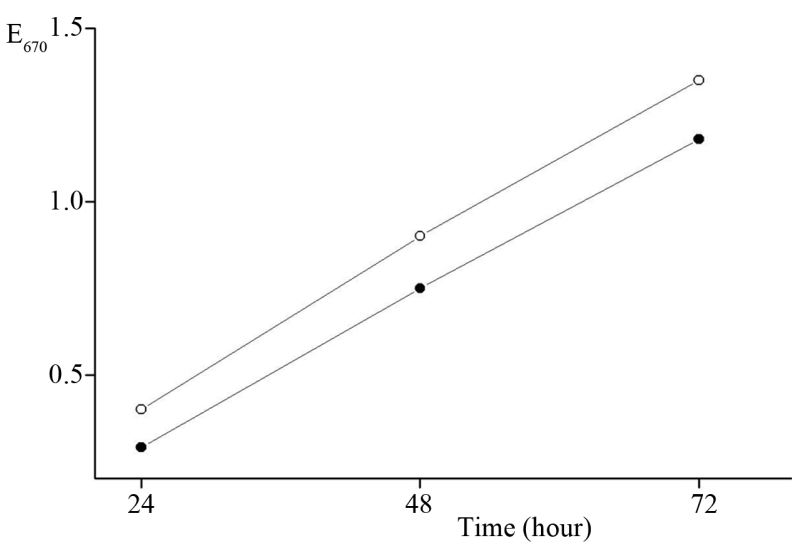

Figure 2. The growth of Serratia marcescens in the broth meat peptone $(\mathrm{O})$, on soybean peptone $(\bullet)$ a biomass in the active growth phase of Serratia marcescens strain 9986 on both media was not differed statistically significant.

on a peptone meat and peptone digest soybean up to $72 \mathrm{~h}$ of the incubation. The accumulation of a biomass in the active growth phase by $48 \mathrm{~h}$ on both media differed insignificantly. In the initial stationary phase the established distinctions in biomass were not statistically significant. The analogous correlation was observed in the pigment biosynthesis since a low price of peptone soybean as a vegetable raw material was suitable fully for fermentation and pigment biosynthesis.

There is the correlation of the pigment accumulation and $\mathrm{pH}$ of the culture medium. As shown in Figure 3 in the first $24 \mathrm{~h}$ of incubation the culture growth on both media was accompanied by a decrease of $\mathrm{pH} 6.5$ - 6.6. Subsequently, the alkalinity of the media during the all course of growth was up to $\mathrm{pH} 7.5-7.0$ and $\mathrm{pH} 7.7-7.2$ on peptones meat and from soybean, respectively. Therefore, $\mathrm{pH}$ nutrient medium is one of the determining factors in the technology of pigment biosynthesis [16].

\section{Determination the Size of the Pigment Protein Particles}

The hydrodynamic diameter of pigment protein complex was revealed by the method of the dynamic light scattering (DLS). The hydrodynamic diameter of the pigment protein samples within the limits of $7.5-8.0 \mathrm{~nm}$ was shown (Figure 4). In dependence on protein structure and density the globular proteins of such size of the molecules could be characterized by molecular mass 100 $200 \mathrm{KDa}$ [17]. Our results could be interpreted as a complex of pigment and protein by molecular mass a little smaller than $100 \mathrm{KDa}$ basing on results of DLS. The revealed complex consisting from particles of diameter $7.5-8.0 \mathrm{~nm}$ was in a lower range limits. The results of DLS also showed that the surfactant sample was characterized by the mean hydrodynamic diameter $\left(\mathrm{D}_{\mathrm{H}}\right)$ of particles about $6 \mathrm{~nm}$ which come to an agreement with 


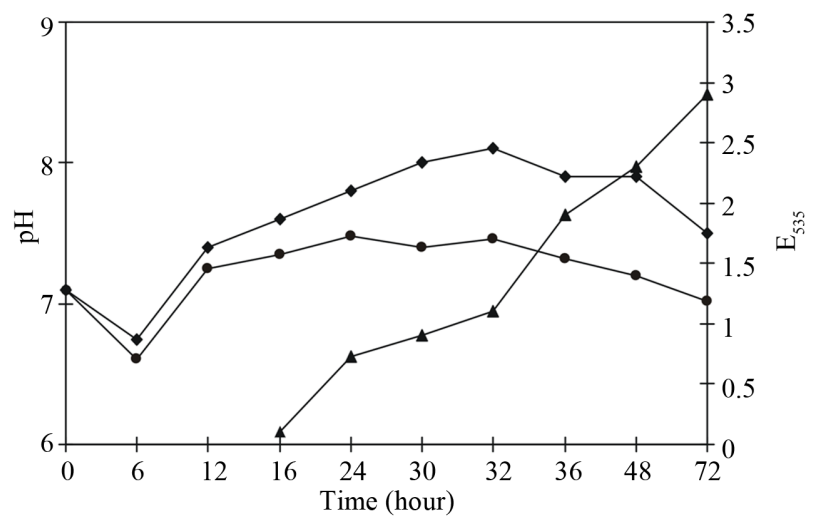

Figure 3. The biosynthesis of prodigiosin and the course of $\mathrm{pH}$ in the broth meat peptone $(\bullet)$, soybean peptone $(\bullet)$, prodigiosin $(\boldsymbol{\Delta})$ In the first hours of the incubation of Serratia marcescens $\mathrm{pH}$ of the media were descended up to 6.5 - 6.6. Thereupon $\mathrm{pH}$ in the growing culture is up to $7.5-7.0$ and $7.7-7.2$ on peptone meat and soybean, respectively. Optimal pigment biosynthesis $(\boldsymbol{\Delta})$ depended on $\mathrm{pH}$ nutrient medium.

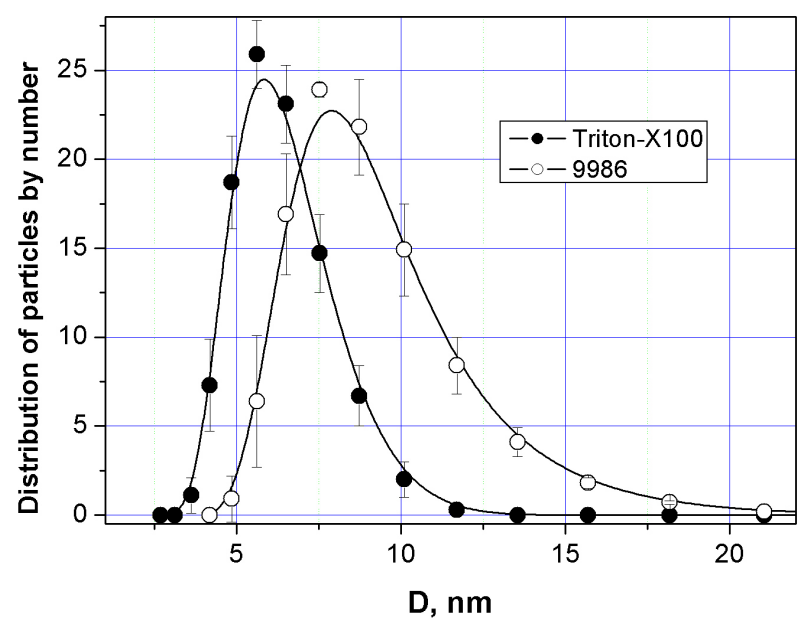

Figure 4. Mean hydrodynamic diameter (nm) of particles isolated from Serratia marcescens strain 9986. Triton X-100 (•) and pigment protein complex $(\mathrm{O})$. Pigmented cells were suspended in $10 \mathrm{mM}$ Triton-X100 and the lysate was centrifuged at $9200 \mathrm{~g}$. The supernatant was saturated by $\left(\mathrm{NH}_{4}\right)_{2} \mathrm{SO}_{4}-0,2 \mathrm{~N}$ (saturation). The colored of pigment protein fraction was resuspended in the bidisllate. The hydrodynamic size of pigment protein particles $(O)$ was measured (by method of dynamic light scatterning (DLS), Malvern Instruments Ltd., Malvern, UK) and the size of micelles of Triton X100 (•).

the size of micelles of Triton $\mathrm{X}-100$ as was shown in literature $[18,19]$.

\subsection{Preparation of Prodigiosin from Biomass}

As it was seen earlier, Serratia marcescens determines pigmentation in correlation with growth conditions namely carbon source and nitrogen, the regular variation of $\mathrm{pH}$ in the whole period of fermentation, temperature, illumination etc. For strain 9986 of Serratia marcescens the optimal biosynthesis of prodigiosin was observed by 50 - 54 hours of the incubation and at take one's temperature $28^{\circ} \mathrm{C}$. The pigment yield $0.2-0.4 \mathrm{mg} \cdot \mathrm{l}^{-1}$ from culture medium was obtained on a meat peptone-glycerol broth in the batch culture under aerobic conditions. Next essential stage of the downstream procedure was focused on the elaboration of the pigment extraction from biomass to meet technological requirements of the polymer coloration.

The technology of pigment isolation consisted from the treatment of crude biomass by detergents. Originally the growing culture at 50 - 54 hours of incubation was sedimented by centrifugation to remove the cell debris. The detergent ionic SDS and the nonionic Triton X-100 for the crude biomass to screen the extractive biomass were added [15,20,21]. After regular distribution during half an hour, the solubilizable pigment suspension was tested on the lightfastness of prodigiosin. The selected ionic surfactant SDS was more effective to the lightfastness of pigment by comparison with Triton X-100 (Table 1). Thus, ionic detergent SDS in the concentration of $0.1 \%-0.5 \%$ to the crude biomass was used. Less concentration of surfactant SDS $(<0.1 \%)$ was caused by the loss of the decoloration prodigiosin in the polyethylene concentrate. The increased content of SDS more $0.5 \%$ in the technological treatment of polymer concentrate resulted in a considerable worsening of the colored polyethylene. The polymer sheet provoked the slide in the rolling process. The offered elaboration is favoured using $0,1 \%$ of SDS in the technological process gains thermostability of the colored polyethylene sheet and the concentrate.

\subsection{Working of Dyeing the Polyolefines by Prodigiosin}

Prodigiosin pigment preparation as a thin suspension (paste) was introduced available to polyethylene concentrate. This was conducived to negligible quantity aglomerates in the polymer ware. The molecular mass of the introduced pigment in the polyethylene was smaller than $100 \mathrm{KDa}$ as shown [8].

According to the technological method the colored concentrate $4.0 \%$ - $8.0 \%$ mass was introduced into the melted down polymer. The time of rolling process was 20 - 25 min. The manufactured polyethylene concentrates and the colored polyethylene concentrate by prodigiosin preparation were conformed to the technological tests (Table 2). Dielectric tests of colored masterbatches corresponded to the experimental data and technical standards (Table 3). Besides in the process of manufacture, the pigmented spicemens of the polymer concentrates have been painted uniformely by prodigiosin and 
Table 2. Tests with colored polyethylene masterbatches.

\begin{tabular}{|c|c|c|c|}
\hline $\begin{array}{l}\text { Composition of polyethylene } \\
\text { ( } \% / \text { mass) }\end{array}$ & $\begin{array}{l}\text { Melt flow index of } \\
\text { concentrate (g/10 min) }\end{array}$ & $\begin{array}{l}\text { Amount of agglomerates } \\
>0.2 \mathrm{~mm} \text { and }<0.5 \mathrm{~mm} \text { in size, } \\
\text { amount no more than }\end{array}$ & $\begin{array}{l}\text { Thermal stability of coloration, } \\
\text { not less than } 15 \text { min at } \\
220^{\circ} \mathrm{C} 3 \text { min at } 250^{\circ} \mathrm{C}\end{array}$ \\
\hline $\begin{array}{c}\text { Prototype-Polyethylene (LDPE)—95.0 } \\
\text { Varnish ruby—5.0 }\end{array}$ & $0.5-3.0$ & $\begin{array}{l}60.0(>0.2) \\
2.0(<0.5)\end{array}$ & No changes \\
\hline $\begin{array}{c}\text { Polyethylene-95.0 } \\
\text { Pigment preparation—5.0 }\end{array}$ & 2.7 & $3.0-0.0$ & No changes \\
\hline $\begin{array}{l}\text { Ultratene- }-90.0 \\
\text { Pigment preparation-10.0 }\end{array}$ & 4.7 & $3.5-0.0$ & No changes \\
\hline
\end{tabular}

Table 3. Dielectric tests with colored polyethylene masterbatches.

\begin{tabular}{ccc}
\hline Test & Standard & Polyethylene colored by pigment preparation \\
\hline $\begin{array}{c}\text { The loss tangent of a dielectric at frequency } 10^{6} \mathrm{~Hz} \text {, not more than } \\
\text { Dielectric permittivity at frequency } 10^{6} \mathrm{~Hz} \text { not more than } \\
\begin{array}{c}\text { Electric strength at alternating voltage of } \\
\text { frequency } 50 \mathrm{~Hz}, \mathrm{kV} / \mathrm{mm} \text {, not less than }\end{array}\end{array}$ & 0.0006 & $0.00034-0.00042$ \\
\end{tabular}

the migratory capacity of pigment from polymer was absent during some years. According to the physical, mechanical parameters and dielectric properties the masterbatches met the standard requirements of cable materials. These results indicate that according to elaborated method the prodigiosin preparation can be considered as a novel type of biological dye-stuff.

The results from Table 4 showed that prodigiosin content in the coloring polymer was very low (mg \% mass) than in application to synthetic organic dyes utilizing in the chemical industry. This advantage in the colored polymer results in its minimal influence on the technological properties of the dyeing concentrate and masterbatches (thermal stability, dielectric etc.).

This search is related to prodigiosin red pigment and based on the current state of our knowledge. In the present industry the red polyethylene masterbatches include high toxic dyes. New resources in the technology for coloration of polymers with the ecologically safe microbe pigments have offered the following radically novel aspects. It is essentially important to note that prodigiosin in the process of fermentation is synthetised as microbe metabolite unlike the organic dyes the synthesis of which is the multiple stage process. The pigments of microorganisms in their composition belong to derivatives of the ordinary metabolites or cellular components and they are ecologically safety compounds which offer principal advantage over other synthetic dye-stuff. However, the microbe pigments being secondary metabolites are synthesized and produced maximum in the period of the stationary growth phase and further they are not metabolized. Serratia marcescens strain 9986 is a producer of prodigiosin bright red pigment which was used as a dye of polyethylene. The fermentation process of microbial strain and the pigment biosynthesis are car-
Table 4. Consumption of pigment concentrates in the colored polyethylene.

\begin{tabular}{cccc}
\hline $\begin{array}{c}\text { Organic } \\
\text { pigments }\end{array}$ & $\begin{array}{c}\text { Pigment } \\
\text { Name }\end{array}$ & $\begin{array}{c}\text { Pigment } \\
\text { content in } \\
\text { concentrate } \\
(\%)\end{array}$ & $\begin{array}{c}\text { Content of } \\
\text { concentrate } \\
\text { in masterbatche } \\
(\%)\end{array}$ \\
\hline 506 dark-blue & Phtalocyanine & 2.5 & 8.0 \\
561 dark-blue & Phtalocyanine & 2.5 & 4.0 \\
Varnish ruby & Varnish & 5.0 & 8.0 \\
$\begin{array}{c}\text { Pigment } \\
\text { preparation }\end{array}$ & Prodigiosin & $1.5-2.0 \times 10^{-3}$ & 4.0 \\
\hline
\end{tabular}

ried out under the strictly controlled conditions. The period of fermentation is shorter in comparison with other biological producers (fungi, algae). The consumption of pigment preparation is more economical in the technology of the dyeing of polymer concentrates. The lower pigment content in the colored concentrates and masterbatche renders smaller influence upon technological parameters of polymer. Other advantages of these method excepting of the rapid cell growth, inexpensive culture media, and a fermentation process that can be easily scaled up to produce industrial quantities of the microbe pigment from target product. In addition, the elaborated method for coloration of polyolefines described here is more effective with minimal effect on an environment than the existing methods in application to organic dyes.

\section{CONCLUSION}

The biosynthesis of prodigiosin was closely connected with growth parameters which were necessary and intended correctly. A pigment yield $0.2-0.4 \mathrm{mg} \cdot \mathrm{l}^{-1}$ from culture medium was obtained on a meat peptone-glycerol 
broth in the batch culture under the aerobic conditions. The elaborated method of the coloration of polyethylene by prodigiosin preparation allowed carrying out the articles of common use complying with the technological standard. The assortment and the application of novel polyethylene concentrates and masterbatches based on the coloration by bacterial pigment are expanded including raw material supply and appropriate innovations in the chemical industry.

\section{ACKNOWLEDGEMENTS}

This work was support. by firm J-S Co Kazanorgsynthes. The authors would like to thank chief technologist N. N. Valiyeva for her helpful technological elaboration and insightful discussion of obtained technological results.

\section{REFERENCES}

[1] Spolaore, P., Joannis-Cassan, C., Duran, E. and Isambert, A. (2006) Rewiew commercial application of microalgae. Journal of Bioscience and Bioengeering, 100, 87-96.

[2] Grimont, P.A.D. and Grimont, F. (1984) Bergey’s manual of systematic bacteriology. The Williams \& Wilkins Co Baltimore, 477-484.

[3] Khanafari, A., Assadi, M.M. and Fakhr, F.A. (2006) Review of prodigiosin, pigmentation in Serratia marcescens. Journal of Biological Sciences, 6, 1-13.

[4] Williams, R.P., Gott, C.L. and Green, J.A. (1961) Studies on pigmentation of Serratia marcescens. Journal Bacteriology, 81, 376-389.

[5] Williams, R.P., Gott, C.L., Quadri, S.M.H. and Scott, R.H. (1971) Influence of temperature and type of growth medium on pigmentation of Serratia marcescens. Journal Bacteriology, 106, 438-443.

[6] Vinâs, M., Loren, J. and Giunea, J. (1983) Particulatrbound pigment of Serratia marcescens and its association with the cellular envelopes. Microbios Letters, 24, 19-26.

[7] Bennett, J.W. and Bentley, R. (2000) The story of prodigiosin. Advance of Applied Microbiology, 47, 1-32. http://dx.doi.org/10.1016/S0065-2164(00)47000-0

[8] Ryazantseva, I.N., Saakov, V.S., Andreyeva, I.N., Ogorodnikova, T.I. and Zuev, Y. (2012) Response of pigmented Serratia marcescens to the illumination. Journal of Photochemistry and Photobiology B: Biology, 106, 1823. http://dx.doi.org/10.1016/j.jphotobiol.2011.08.006

[9] Herbst, W. and Hunger, K. (1995) Industrielle organische Pigmente. 2rd Edition, VCH, Modern Plastics No. 12, 284.
[10] Moraes, C.C. and Kalil, S.J. (2009) Strategy for a protein purification design using C-phycocyanin extract. Bioresource Technology, 100, 5312-5317. http://dx.doi.org/10.1016/j.biortech.2009.05.026

[11] Bobreshova, E.E., Kudryashov, V.N., Ryazantseva, I.N., Andreyeva, I.N., Valiyeva, N., Ogorodnikova, T.I. and Moshkova, Y.N. (2008) Microbial pigments to chemical technology. Kazan Press, 58-59.

[12] Giri, A.V., Anandkumar, G.M. and Pennathur, G. (2004) A novel medium for the enhanced cell growth and production of prodigiosin from Serratia marcescens isolated from soil," BMC Microbiology, 4, 11-15. http://dx.doi.org/10.1186/1471-2180-4-11

[13] Bunting, M.J. (1940) A description of some colour variants produced by Serratia marcescens Strain 274. Journal Bacteriology, 40, 57-68.

[14] Cho, L.K.N., Lowe, J.A., Maguire, R.B. and Tsang, J.C. (1987) Relationship of prodigiosin condensing enzyme activity to the biosynthesis of prodigiosin and its precursors in Serratia marcescens. Experientia, 43, 397-409. http://dx.doi.org/10.1007/BF01940425

[15] Feng, J.S., Webb, J.W. and Tsang, J.C. (1982) Enhancement of sodium dodecyl sulfate of pigment formation in Serratia marcescens 08. Applied and Environment of Microbiology, 43, 850-854.

[16] Sole, M., Rius, N., Francia, A. and Loren, J.G. (1994) The effect of $\mathrm{pH}$ on prodigiosin production by non-proliferating cells of Serratia marcescens. Letters Applied of Microbiology, 19, 341-344. http://dx.doi.org/10.1111/j.1472-765X.1994.tb00470.x

[17] Erickson, H.P. (2009) Size and shape of protein molecules at the nanometer level determined by sedimentation, gel filtration, and electron microscopy. Biological Procedures Online, 11, 32-51.

[18] Streletzky, K. and Phillies, G.D.J. (1995) Temperature dependence of Triton X100 micelle size hydration. Langmuir, 11, 42-47. http://dx.doi.org/10.1021/la00001a011

[19] Charlton, I.D. and Doherty, A.P. (2000) Electrolyte-induced structural evolution of Triton X100 micelles. Journal of Physical Chemistry B, 104, 8327-8332. http://dx.doi.org/10.1021/jp994424v

[20] Silverman, M.P. and Munoz, E.F. (1973) Effect of iron and salt on prodigiosin synthesis of Serratia marcescens. Journal Bacteriology, 114, 999-1005.

[21] Matsuyama, T., Murakami, T., Fujita, M., Fujita, S. and Yano, J. (1986) Extracellular vesicle formation and biosurfactant production by Serratia marcescens. Journal of General Microbiology, 132, 865-875. 